\title{
Identification of Microbiological Activities in Wet Flue Gas Desulfurization Systems
}

\author{
Gregory Martin ${ }^{1 \dagger}$, Shagun Sharma ${ }^{1,2}$, William Ryan ${ }^{1}$, Nanda K. Srinivasan ${ }^{3}$ and \\ John M. Senko ${ }^{1,2,4 *}$ \\ ${ }^{1}$ Department of Biology, The University of Akron, Akron, OH, United States, ${ }^{2}$ Integrated Bioscience Program, The University \\ of Akron, Akron, $\mathrm{OH}$, United States, ${ }^{3}$ Electric Power Research Institute, Palo Alto, CA, United States, ${ }^{4}$ Department \\ of Geosciences, The University of Akron, Akron, OH, United States
}

OPEN ACCESS

Edited by:

Anna-Louise Reysenbach Portland State University, United States

Reviewed by: Nils-Kaare Birkeland, University of Bergen, Norway Hannah Schweitzer,

UiT The Arctic University of Norway,

Norway

*Correspondence: John M. Senko

senko@uakron.edu

${ }^{\dagger}$ Present address: Gregory Martin, Division of Plant and Soil Sciences, Davis College of Agriculture, Natural Resources and Design, West Virginia University, Morgantown, WV United States

Specialty section: This article was submitted to Extreme Microbiology, a section of the journal Frontiers in Microbiology

Received: 03 March 2021 Accepted: 07 June 2021

Published: 28 June 2021

Citation:

Martin G, Sharma S, Ryan W, Srinivasan NK and Senko JM (2021) Identification of Microbiological Activities in Wet Flue Gas Desulfurization Systems. Front. Microbiol. 12:675628. doi: 10.3389/fmicb.2021.675628
Thermoelectric power generation from coal requires large amounts of water, much of which is used for wet flue gas desulfurization (wFGD) systems that minimize sulfur emissions, and consequently, acid rain. The microbial communities in wFGDs and throughout thermoelectric power plants can influence system performance, waste processing, and the long term stewardship of residual wastes. Any microorganisms that survive in wFGD slurries must tolerate high total dissolved solids concentrations (TDS) and temperatures $\left(50-60^{\circ} \mathrm{C}\right)$, but the inocula for wFGDs are typically from fresh surface waters (e.g., lakes or rivers) of low TDS and temperatures, and whose activity might be limited under the physicochemically extreme conditions of the WFGD. To determine the extents of microbiological activities in wFGDs, we examined the microbial activities and communities associated with three wFGDs. $\mathrm{O}_{2}$ consumption rates of three WFGD slurries were optimal at $55^{\circ} \mathrm{C}$, and living cells could be detected microscopically, indicating that living and active communities of organisms were present in the WFGD and could metabolize at the high temperature of the WFGD. A 16S rRNA gene-based survey revealed that the wFGD-associated microbial communities included taxa attributable to both thermophilic and mesophilic lineages. Metatranscriptomic analysis of one of the wFGDs indicated an abundance of active Burholderiaceae and several Gammaproteobacteria, and production of transcripts associated with carbohydrate metabolism, osmotic stress response, as well as phage, prophages, and transposable elements. These results illustrate that microbial activities can be sustained in physicochemically extreme wFGDs, and these activities may influence the performance and environmental impacts of thermoelectric power plants.

\section{Keywords: flue gas desulfurization, thermophiles, thermoelectricity, water quality, coal combustion}

\section{INTRODUCTION}

Industrialized nations rely heavily on coal-fired thermoelectric power plants to support energy needs. In the United States, $24 \%$ of electricity is furnished by coal burning power plants (U.S. Energy Information Agency (USEIA), 2020). Coal combustion remains one of the largest contributors of air pollution including $\mathrm{Hg}$, and acid rain-forming $\mathrm{NO}_{x}$ and $\mathrm{SO}_{2}$ 
(Likens et al., 1996; Srivastava and Jozewicz, 2001). Flue gas (coal exhaust) desulfurization units (FGDs), intended to remove $\mathrm{SO}_{2}$, $\mathrm{NO}_{x}$, and, to a lesser extent, $\mathrm{Hg}^{2+}$, were introduced starting in the 1970s to mitigate the acid rain problem (Srivastava et al., 2006; Córdoba, 2015). In wet FGDs (wFGDs), flue gas is passed into a tank above a limestone or slaked lime slurry, and wetted by spray nozzles, whereby $\mathrm{SO}_{2}$ partitions into the slurry. $\mathrm{Ca}^{2+}$ in the limestone or lime then forms a $\mathrm{CaSO}_{3}$ precipitate slurry, which can then be further oxidized to gypsum $\left(\mathrm{CaSO}_{4} \cdot 2 \mathrm{H}_{2} \mathrm{O}\right)$, with the addition of $\mathrm{O}_{2}$ (also called forced oxidation) (Córdoba, 2015). The scrubbed gas can continue through the top of the system and exits the stack to the atmosphere. The bottom slurry mixture is cycled out of the tank for processing. The solids are dewatered and landfilled or sold for industrial uses such as wallboard, cement, and soil augmentation to offset operational and disposal costs. The liquor, which contains high dissolved solids, and a variety of potentially toxic chemical (e.g., $\mathrm{Hg}$, As, and $\mathrm{Se}$ ) is either recycled into the wFGD system, or purged for halogen removal and treated before discharge to a large water body.

Microorganisms have been observed in wFGDs, but the high temperatures $\left(50-60^{\circ} \mathrm{C}\right)$ induced by the exhaust, and high concentrations of $\mathrm{Ca}^{2+}, \mathrm{Mg}^{2+}, \mathrm{SO}_{4}{ }^{2-}, \mathrm{Cl}^{-}$, and toxic metals make wFGDs harsh environments for microbial growth (Brown et al., 2012; Córdoba, 2015). The microbial communities and activities associated with wFGDs remain poorly understood despite their importance in FGD performance and downstream processing of waste streams (Buchart et al., 2006; Córdoba, 2015; Graves et al., 2017; Gingerich et al., 2018). Most notably, microbial activities in wFGDs have been implicated in the corrosion of unit-associated structures and the "re-emission" of $\mathrm{Hg}$ (Barkay and Wagner-Döbler, 2005; Wu et al., 2010; Moskal, 2011; Moretti and Jones, 2012; Ochoa-González et al., 2013). In the latter process, Hg, which would otherwise be retained in the $\mathrm{wFGD}$ as $\mathrm{Hg}^{2+}$ adsorbed to solids in the slurry is reduced to volatile $\mathrm{Hg}^{0}$, potentially by microbiological activity, and emitted into the atmosphere (Barkay and WagnerDöbler, 2005; Wu et al., 2010; Moretti and Jones, 2012; OchoaGonzález et al., 2013). Despite speculation of the activities of micoorganisms in wFGDs, it remains unclear if they are, in fact, active.

Given the relatively harsh physicochemical conditions associated with the interior of $\mathrm{wFGDs}$ (i.e., high temperatures and dissolved solids concentrations), it is reasonable to expect that microbial abundances and activities associated with these systems would be minimal. Indeed, diversity of microbial communities associated with wFGD slurries is lower compared to those associated with waters that did not experience the relatively harsh conditions of the wFGD interior (Brown et al., 2012). Several classes of organisms detected in wFGDs were similar to those detected in waters used in slurry preparation (lake or river water), indicating that many of the organisms in wFGD slurries were present, but not necessarily active. However, the potential for microbial activity in wFGDs clearly exists. For instance, microorganisms capable of growth in high-sulfate medium at $60^{\circ} \mathrm{C}$ were shown to be more abundant in wFGD slurries than in fresh waters used to fills the wFGDs (Brown et al., 2012). Microbial communities associated with the deposits on the interior walls of wFGDs contained classes of organisms encountered in geothermal settings (Brown et al., 2012). Some of these observations could indicate that microbial activity is minimal in wFGDs, but they also indicate that residence times of fluids in the slurries might be such that the physicochemical conditions of the systems exert some control on the structure of the microbial communities. They also indicate that while the inoculum for wFGDs is derived from less physicochemically extreme ecosystems (i.e., river or lake water and limestone), the relatively harsh conditions of the wFGD interior select for unique, active microbial communities in wFGDs. In summary, past work indicates that microorganisms were present, and some were culturable in wFGDs (Brown et al., 2012), but whether they were active, and the extents of their activities remain unclear. Therefore, the goal of this work was to understand the composition and activities of microorganisms associated with wFGDs, by (1) establishing how organisms in wFGDs differ from the freshwater sources of slurry water, and (2) determining if organisms in wFGDs are alive and actively metabolizing.

\section{MATERIALS AND METHODS}

\section{Sampling Sites and Collection}

In August 2016, samples were collected from three coal-fired thermoelectric power plants on the Ohio River, all of which are within a $210 \mathrm{~km}$ stretch of the river, and operate multiple $w F G D s$ with the river as their source water. The temperature of all the wFGDs is maintained near $55^{\circ} \mathrm{C}$. The first site, $\mathrm{S}$, relies on limestone wFGD with forced air oxidation, the second site, $M$, uses a magnesium lime mixture in its wFGDs, and the third site, $\mathrm{P}$, operates a modified magnesium lime system with higher $\mathrm{MgOH}$ levels. Thirty $50 \mathrm{~mL}$ vials and two $1 \mathrm{~L}$ bottles of slurry were collected from bleed valves adjacent to wFGDs of sites $\mathrm{S}$, $\mathrm{M}$, and P. Two $1 \mathrm{~L}$ bottles of river water were collected near the system intake at sites $S$ and P. All samples were collected in sterile containers and transported on ice to The University of Akron (UA) for further analysis. Immediately upon return to the laboratory, for each site, $5 \mathrm{~mL}$ of sample was filter sterilized into $5 \mathrm{~mL}$ of $0.5 \mathrm{M} \mathrm{HCl}$ for atomic absorption spectrometry analysis, $5 \mathrm{~mL}$ of sample was filter sterilized in preparation for anion quantification (described below), and samples intended for DNA extraction were stored in a $-80^{\circ} \mathrm{C}$ freezer, all other samples were placed in the refrigerator. A $20 \mathrm{~mL}$ sample from Unit $\mathrm{P}$ that was intended for metatranscriptomic analysis was suspended in $20 \mathrm{~mL}$ DNA/RNA Shield (Zymo Research, Irvine, CA, United States) RNA stabilization solution before transport on ice to UA $(\leq 2 \mathrm{~h})$, where it was then stored at $-80^{\circ} \mathrm{C}$ before further processing.

\section{wFGD Slurry Incubations}

Aerobic microbial activities in slurries were determined by measuring $\mathrm{O}_{2}$ consumption rates using a Micro-Oxymax respirometer (Columbus Instruments, Columbus, $\mathrm{OH}$, United States) (Poncelet et al., 2013). Temperatures were maintained in a water bath and microbiological activities were 
deactivated by autoclaving wFGD slurry for negative controls. Slurry incubations were carried out at $20,40,55$, and $70^{\circ} \mathrm{C}$ in triplicate for non-sterile incubations and duplicate for deactivated ones.

\section{Microbial Enumerations and Enrichments}

Microbial cell abundances in wFGD slurries were determined by total live/dead cell counts after staining samples with SYTO 9 green-fluorescent nucleic acid stain and propidium iodide redfluorescent nucleic acid stain (Thermo Scientific Inc., Waltham, MA, United States), followed by visualization and cell counting on an Olympus BX53F fluorescent light microscope (Olympus Life Science Solutions, Waltham, MA, United States). Briefly, $0.5 \mathrm{~mL}$ of each sample was stained according to the BACLight protocol and then transferred into wells on TEKON black Teflon coated 12 well slides (TEKON Inc., Myakka City, FL, United States). Five random grids from five wells were counted and then averaged per sample, for both live and dead stains. Only cells that were brightly stained and clearly differentiated from the background florescence were included in the counts. A test case was also conducted, where live Shewanella oneidensis cells were added to slurry in a 1:1 ratio, and stained to ensure that cells could be differentiated from slurry solid phases (Supplementary Figure 1). Cell counts per field are shown in Supplementary Table 1.

Aerobic enrichments from wFGD slurries were carried out with culture medium ( $\mathrm{pH}$ 6.5) that contained $\mathrm{CaCO}_{3}$ (3 g/L), NH $4 \mathrm{Cl}(0.16 \mathrm{~g} / \mathrm{L}), \mathrm{K}_{2} \mathrm{HPO}_{4}(0.09 \mathrm{~g} / \mathrm{L}), \mathrm{NaH}_{2} \mathrm{PO}_{4}$ $(0.06 \mathrm{~g} / \mathrm{L}), \mathrm{MgBr}_{2} \cdot 6 \mathrm{H}_{2} 0(0.09 \mathrm{~g} / \mathrm{L}), \mathrm{MgSO}_{4} \cdot 7 \mathrm{H}_{2} 0(17 \mathrm{~g} / \mathrm{L})$, and $\mathrm{MgCl}_{2} \cdot 6 \mathrm{H}_{2} \mathrm{O}(6 \mathrm{~g} / \mathrm{L})$, vitamins and trace metals (Tanner, 1997), and glucose $(0.9 \mathrm{~g} / \mathrm{L})$ or acetate $(1.64 \mathrm{~g} / \mathrm{L})$ as electron donors and carbon sources. Enrichments were incubated at $50^{\circ} \mathrm{C}$, and maintained through six transfers before they were harvested and characterized using $16 \mathrm{~S}$ rRNA gene sequence surveys.

\section{Nucleic Acid-Based Microbial Community Characterization}

Before nucleic acid extraction for 16S rRNA gene surveys, suspended solids from the wFGD slurries or enrichment cultures were concentrated by centrifugation at $3000 \times g$ for $10 \mathrm{~min}$ and planktonic organisms in Ohio River wFGD source water were concentrated by filtration $(0.2 \mu \mathrm{m})$. Pellets and filters were stored at $-70^{\circ} \mathrm{C}$ until DNA was extracted using MoBio PowerBiofilm DNA isolation kits (MoBio Laboratories, Inc., Carlsbad, CA, United States), and DNA was quantified using a Qubit 3.0 Fluorometer (Thermo Scientific Inc., Waltham, MA, United States). DNA from all wFGDs and source water samples was shipped to Molecular Research LP (MR DNA, Shallowater, TX, United States) for Illumina MiSeq sequencing (Illumina, Inc., San Diego, CA, United States), where barcoded 515F, 806R primers (Caporaso et al., 2011) were used to amplify partial $16 \mathrm{~S}$ rRNA genes through a 28 cycle PCR using the HotStarTaq Plus Master Mix Kit (Qiagen, United States) programed for $94^{\circ} \mathrm{C}$ for $3 \mathrm{~min}$, then $28 \mathrm{cycles}$ of $94^{\circ} \mathrm{C}$ for $30 \mathrm{~s}, 53^{\circ} \mathrm{C}$ for $40 \mathrm{~s}$, and $72^{\circ} \mathrm{C}$ for $1 \mathrm{~min}$, and $72^{\circ} \mathrm{C}$ for $5 \mathrm{~min}$ final elongation. Multiple samples were pooled in equal proportions based on their molecular weight and DNA concentrations, as determined by a $2 \%$ agarose gel. The Illumina DNA library was prepared from calibrated AMpure XP bead purified pooled samples. Amplicons were sequenced on an Illumina MiSeq, following the manufacturer's guidelines, and then barcodes were depleted, $<150$ bp sequences were removed, sequences with ambiguous base calls were removed, and the sequences were denoised and chimeras removed using the quality filtering strategy described by Bokulich et al. (2013).

$16 \mathrm{~S}$ rRNA gene sequences were processed using default parameters of QIIME 1 scripts (Caporaso et al., 2010). Operational taxonomic units based on $97 \%$ sequence similarity $\left(\mathrm{OTU}_{0.03}\right)$ were picked de novo and assigned to taxonomic units using the RDP Classifier 2.2 with the SILVA database (Wang et al., 2007; Edgar, 2010; Werner et al., 2012). 86,851-135,615 sequences were obtained from the slurries or river water samples, and within them, 1,665-4,123 unique OTUs were identified (Supplementary Table 2). wFGD sequence libraries from each sample were rarefied to 24,439 sequences, and Shannon diversity indices were calculated (Lozupone and Knight, 2005; Price et al., 2010; Caporaso et al., 2011; Quast et al., 2013). Abundant $\mathrm{OTU}_{0.03}$ in libraries were compared to sequences in the National Center for Biotechnology Information (NCBI) database using the Basic Local Alignment Search Tool (BLASTN; Altschul et al., 1997).

For metatranscriptomic analysis of Unit P microorganisms, slurry sample was shipped on dry ice to MR DNA Lab for total RNA sequencing. Slurry solids were concentrated by centrifugation and total RNA was extracted from the pellet using the MoBio RNA PowerSoil Total RNA Isolation Kit (MoBio Laboratories, Inc., Carlsbad, CA, United States). DNA contamination was removed using Baseline-ZERO DNase (Lucigen Corporation, Middleton, WI, United States) and samples were purified using RNA Clean and Concentrator Columns (Zymo Research, Irvine, CA, United States). Next, whole transcriptome amplification was conducted using QuantiTect Whole Transcriptome Kit (Qiagen, Germantown, MD, United States) and Nextera DNA Sample preparation. Double stranded cDNA concentrations were measured with a Qubit 3.0 Fluorometer (Thermo Scientific Inc., Waltham, MA, United States), and the diluted samples were fragmented, and adapter sequences and unique indices were added during a 5 cycle PCR. Final library concentrations were measured with a Qubit 3.0 Fluorometer (Thermo Scientific Inc., Waltham, MA, United States) and average library size was determined with an Agilent 2100 Bioanalyzer (Agilent Technologies, Santa Clara, CA, United States). Libraries were pooled in equimolar ratios of $2 \mathrm{nM} .10 \mathrm{pM}$ of the pooled library was clustered using Illumina cBot and paired end sequenced for 500 cycles on an Illumina HiSeq 2500 system.

Unpaired sequence reads were processed using MetaGenomics Rapid Annotation using Subsystem Technology (MG-RAST) pipeline version 4.0 ${ }^{1}$ (Meyer et al., 2008). Quality control included removal of sequences with greater than 10 ambiguous bases per read and dereplication of duplicate

\footnotetext{
${ }^{1}$ https://www.mg-rast.org
} 
sequences with identical sequences in the $50 \mathrm{bp}$. After quality control, a total of $695 \mathrm{Mbp}$ were recovered, which included $4.1 \times 10^{6}$ sequences of mean length $170 \mathrm{bp}$. Taxonomy of $16 \mathrm{~S}$ rRNA was assigned based on the M5nr database (Wilke et al., 2012) using BLASTX in MG-RAST with an $e$-value of $10^{-5}$ and minimum identity of $60 \%$, revealing 679 predicted rRNA features. Functional assignments were made to other reads based on the SEED database (Overbeek et al., 2005) using BLASTX in MG-RAST with an $e$-value of $10^{-5}$, revealing 74,406 predicted protein features. Supplementary Table 3 provides metatranscriptomic metadata. Both the Unit $\mathrm{P}$ metatranscriptome and partial 16S rRNA gene sequences reported in this paper are available in the Sequence Read Archive (SRA) under BioProject accession number PRJNA689629.

\section{Analytical Techniques}

$\mathrm{Cl}^{-}, \mathrm{NO}_{3}{ }^{-}$, and $\mathrm{SO}_{4}{ }^{2-}$ concentrations were measured with a Dionex ICS-1100 Basic Integrated IC System (Thermo Fisher Scientific Inc., Sunnyvale, CA, United States). Dissolved Ca and $\mathrm{Mg}$ concentrations were measured with a Perkin Elmer AAnalyst 700 Atomic Absorption Spectrometer (PerkinElmer Corp., Norwalk, CT, United States). pH was measured with a VWR $^{\circledR}$ SympHony ${ }^{\mathrm{TM}}$ B10P Benchtop Meter (VWR Int., Radnor, PA, United States). Glucose concentrations were determined using colorimetric method with a glucose assay kit (STA680, Cell Biolabs, Inc., San Diego, CA, United States) on a spectrophotometer (Spectra max 384 plus; Molecular devices, Sunnyvale, CA, United States) at $540 \mathrm{~nm}$. Changes in the acetate concentrations in the medium were quantified by highperformance liquid chromatography, using a Shimadzu LC-10A HPLC system (Shimadzu Scientific Instruments, Inc., Columbia, MD, United States) with Aminex HPX-87H column (300 mm, $7.8 \mathrm{~mm}$; Bio-Rad Laboratories, Inc., Hercules, CA, United States) with $0.008 \mathrm{M} \mathrm{H}_{2} \mathrm{SO}_{4}$ as a mobile phase, a flow rate of $0.6 \mathrm{ml} / \mathrm{min}$, and UV $(254 \mathrm{~nm})$ detection (SPD-10A).

\section{RESULTS AND DISCUSSION}

\section{wFGD Slurry Chemistry}

Samples were collected from three wFGDs of coal-fired thermoelectric power plants, all located in the Ohio River watershed, and designated Units $\mathrm{S}, \mathrm{M}$, and $\mathrm{P}$. Unit $\mathrm{S}$ is a limestone-based wFGD that uses forced air to oxidize calcium sulfite to calcium sulfate (gypsum), and Units $\mathrm{M}$ and $\mathrm{P}$ use lime as a $\mathrm{Ca}$ source for $\mathrm{SO}_{x}$ precipitation and are often enhanced with $\mathrm{MgOH}$ for higher alkalinity. Both types of reactors are characterized by high dissolved solids concentrations, which vary depending on the residence times of solids and liquid phases, coal type, power generation intensity, and operator preferences (Córdoba, 2015). At the time of sample collection, all units contained high sulfate concentrations with slightly acidic $\mathrm{pH}$ (Table 1). While the chloride concentration was low in Unit $\mathrm{S}$, it was high in Units $\mathrm{M}$ and $\mathrm{P}$, likely due to differences in operation, residence time, or coal type (Córdoba, 2015). Despite these differences, at the relatively high operating temperatures (approximately $55^{\circ} \mathrm{C}$ ) and dissolved solids concentrations, these systems represent a pysicochemical extreme environment in comparison to the freshwater (i.e., lake or river) sources of water that are used to fill the reactors (Table 1). While $\mathrm{pH}$ was the only parameter of river water chemistry measured in this work, chloride and sulfate concentrations are typically approximately 0.8 and $0.7 \mathrm{mM}$, respectively, in the large rivers of the Ohio River watershed on which the power plants are located (Ohio River Valley Water Sanitary Commission (ORANCO), 2018). The major anions in the wFGDs are considerably higher than those encountered in freshwater systems (Table 1). However, the wFGDs would not classified as saline environments because that term is generally applied to dissolved $\mathrm{NaCl}$ (e.g., Merino et al., 2019). In the wFGDs, chloride concentrations vary, but sulfate, magnesium, and calcium concentrations are 4-5 times higher than would be encountered in seawater (Table 1).

\section{Microbial Activity in wFGD}

During wFGD startup, water from a nearby source is used for the slurry, and this water is also used to makeup water lost during operation (Ochoa-González et al., 2013; Córdoba, 2015). Therefore, microorganisms associated with relatively low-temperature, fresh water sources are exposed to high temperatures and dissolved solids concentrations in the wFGD (Brown et al., 2012). Such harsh conditions could limit activity of the mostly mesophilic source water-associated microorganisms once in the wFGD. Previously, some evidence of microbial activity was suggested by adipic acid consumption in wFGD slurries (Buchart et al., 2006). Live/dead staining and fluorescence microscopy were used to assess whether cells in all three wFGDs were alive. Units $S$ and $M$ contained approximately 1:1 live:dead (Table 1), with the fewest total cells observed in Unit S (Table 1). Unit P contained the most microbial biomass, and approximately $90 \%$ of the cells were alive (Table 1). As an indicator of microbiological activity, $\mathrm{O}_{2}$ consumption by non-sterile wFGD slurry exceeded that of the autoclaved slurry in all of the incubations, except when Unit $S$ slurry was incubated at $70^{\circ} \mathrm{C}$ (Figure 1). Generally, abiotic $\mathrm{O}_{2}$ consumption (i.e., by autoclaved wFGD slurry) increased with increasing temperature, but the difference between abiotic and biological $\mathrm{O}_{2}$ consumption was greatest at 40 and $55^{\circ} \mathrm{C}$ in all cases. These results indicate that the microbial communities associated with the slurries metabolize optimally at $\mathrm{wFGD}$ operating temperatures, but can also metabolize at lower temperatures. The microbial communities appear to have changed in response to the physical conditions of the wFGDs and metabolize optimally at the relatively high temperatures of these system. Similarly, $\mathrm{O}_{2}$ consumption rates corelated with live cell abundances, with Unit $\mathrm{S}$ exhibiting the least activity, and Unit $\mathrm{P}$ exhibiting the greatest activity (Table 1 and Figure 1).

\section{Microbial Community Composition}

Source waters represent a relatively low-temperature and dissolved solids concentration inoculum for the wFGDs (Brown et al., 2012). Source water for both Units $\mathrm{P}$ and $\mathrm{S}$ contained abundant Actinobacteria, Alphaproteobacteria, and Betaproteobacteria, with composition similar to other observations of the Ohio River watershed 
TABLE 1 | Aqueous chemistry, microbial cell abundances, and non-parametric microbial community diversity indicators of wFGD slurry and source water. All measurements were made on samples collected in August, 2016, except for cations, which were measured in samples collected in August 2015. $\mathrm{n} / \mathrm{d}=$ not determined. Ocean water chemistry is included for comparison to the wFGDs.

\begin{tabular}{|c|c|c|c|c|c|c|c|c|c|}
\hline Sample & $\mathrm{pH}$ & $\begin{array}{c}\mathrm{Cl}^{-} \\
(\mathrm{mM})\end{array}$ & $\begin{array}{l}\mathrm{NO}_{3}^{-} \\
(\mathrm{mM})\end{array}$ & $\begin{array}{c}\mathrm{SO}_{4}{ }^{2-} \\
(\mathrm{mM})\end{array}$ & $\begin{array}{l}\mathrm{Mg}^{2+} \\
(\mathrm{mM})\end{array}$ & $\begin{array}{l}\mathrm{Ca}^{2+} \\
(\mathrm{mM})\end{array}$ & $\begin{array}{l}\text { Live cell } \\
\text { abundance } \\
\text { (cell/mL) }\end{array}$ & $\begin{array}{l}\text { Dead cell } \\
\text { abundance } \\
\text { (cell/mL) }\end{array}$ & $\begin{array}{l}\text { Shannon } \\
\text { index }\end{array}$ \\
\hline Unit S & 5.44 & 0.0 & 4.6 & 124 & 163 & 104 & $1.8 \times 10^{6}$ & $2.7 \times 10^{6}$ & 6.02 \\
\hline Unit M & 6.87 & 98 & 0.0 & 193 & 167 & 45 & $7.5 \times 10^{6}$ & $5.4 \times 10^{6}$ & 4.17 \\
\hline Unit P & 5.82 & 110 & 0.0 & 205 & 402 & 44 & $4.4 \times 10^{7}$ & $4.9 \times 10^{6}$ & 5.34 \\
\hline S Source $^{1}$ & 7.73 & 0.8 & 0.01 & 0.7 & 0.4 & 0.8 & $n / d$ & $n / d$ & 6.80 \\
\hline P Source ${ }^{1}$ & 7.75 & 0.8 & 0.01 & 0.7 & 0.4 & 0.8 & $n / d$ & $\mathrm{n} / \mathrm{d}$ & 6.08 \\
\hline Ocean water ${ }^{2}$ & 7.84 & 550 & 0.0 & 28 & 53 & 10 & & & \\
\hline
\end{tabular}

${ }^{1}$ All values except $\mathrm{pH}$ are from Ohio River Valley Water Sanitary Commission (ORANCO) (2018).

${ }^{2}$ Values are from Turekian (1968).

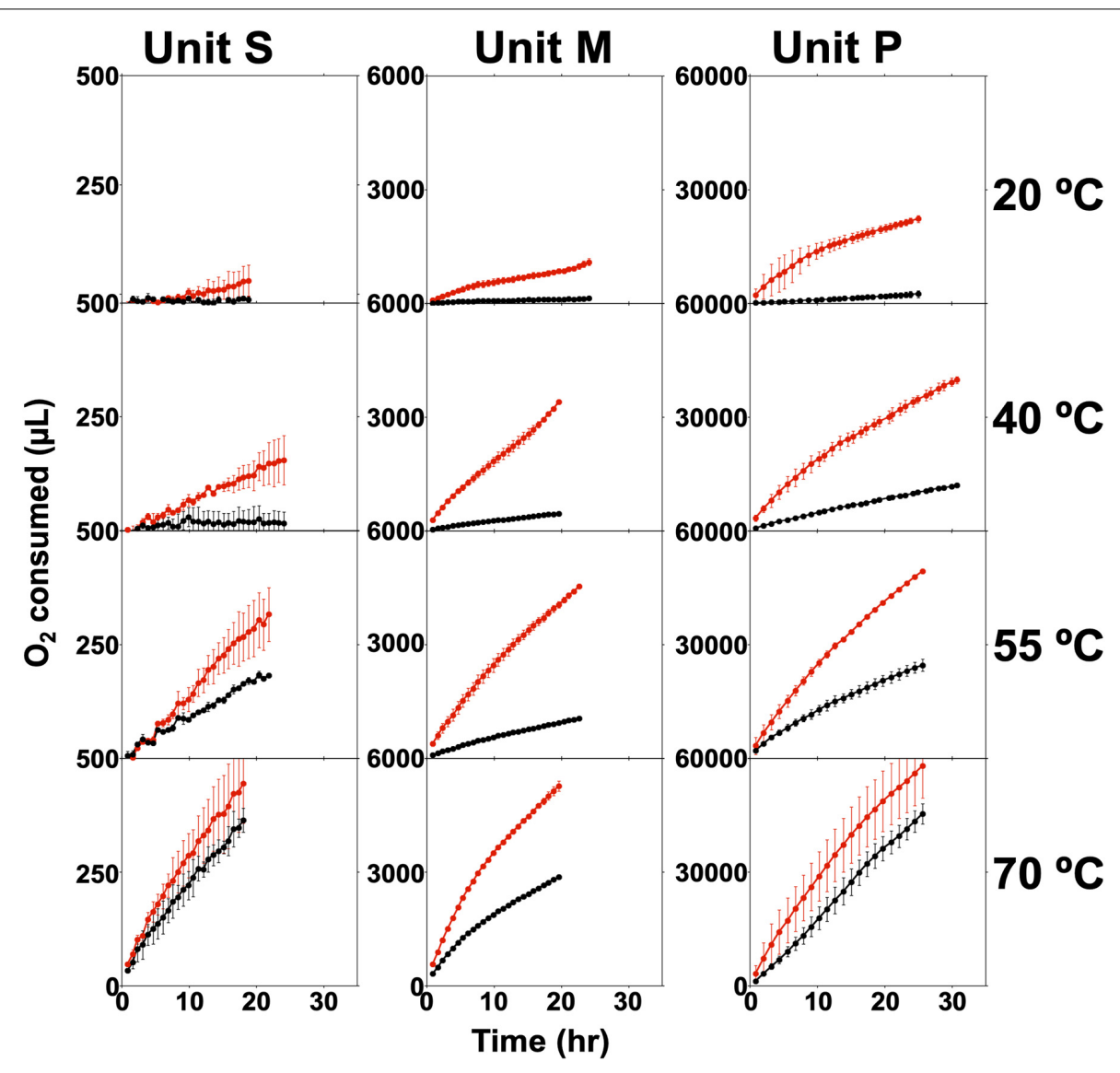

FIGURE $1 \mid \mathrm{O}_{2}$ consumption in non-sterile (red) and autoclaved (black) wFGD slurry material from Unit $\mathrm{S}$, Unit $\mathrm{M}$, and Unit $\mathrm{P}$ incubated at $20,40,55$, and $70^{\circ} \mathrm{C}$ Error bars represent one standard deviation of triplicate (non-sterile) or duplicate (autoclaved) incubations.

(e.g., Schultz et al., 2013; Stannish et al., 2016). In both river libraries, Actinobacteria were predominantly the aquatic HGCI (Warnecke et al., 2004) and CL500-29 (Xu et al., 2018). Alphaproteobacteria were predominantly the widely distributed uncultured SAR11 freshwater clade LD12 (Salcher et al., 2011), and Betaproteobacteria were predominantly the freshwater planktonic Polynucleobacter (Hahn et al., 2016). Taken together, the source water-associated microbial communities were typical of freshwater systems. The Shannon diversity indices of wFGDs were slightly lower than those of the source water (Table 1), and the wFGDs exhibited different phylum-level community composition patterns than the source water (Figure 2A). Both of these differences were likely induced by the relatively harsh physicochemical conditions of the wFGDs. Archaea- and Eukarya-assignable sequences comprised $\leq 0.05 \%$ of the sequences in our libraries. 
While all three wFGD slurries contained abundant phylotypes attributable to Alphaproteobacteria and Betaproteobacteria (Figure 2A), genus-level taxonomic assignments within these phyla varied among the three units. Albidovulum(Alphaproteobacteria), Gallionella-, Thiomonas-, and Hydrogenophaga- (Betaproteobacteria) affiliated phylotypes were abundant in Unit S, Rhodobacter- (Alphaproteobacteria) and Hydrogenophilus- (Betaproteobacteria) affiliated phylotypes were abundant in Unit M, and Sphingomonas- (Alphaproteobacteria), Ralstonia-, and Tepidimonas- (Betaproteobacteria) affiliated phylotypes were abundant in Unit P. Pseudomonas(Gammaproteobacteria), and Atopostipes- (Firmicutes) affiliated phylotypes were also abundant in Unit P. The most prominent taxa in Units S and M were mostly lithotrophic and/or thermophilic (Albidovulum, Gallionella, Thiomonas, Hydrogenophaga, Rhodobacter, and Hydrogenophilus; Willems et al., 1989; Hallbeck and Pedersen, 1991; Hayashi et al., 1999; Albuquerque et al., 2002; Ghosh and Dam, 2009; Arsène-Ploetz et al., 2010), while those in Unit P were mostly organotrophic mesophiles (except for Tepidomonas; Schönfeld et al., 2003; Cotta et al., 2004; Leys et al., 2004; Chen et al., 2013; AlMailem et al., 2019), which would not be expected to be active. Nevertheless, Unit $\mathrm{P}$ exhibited the most abundant live cells and $\mathrm{O}_{2}$ consumption activity (Table 1 and Figure 1). At the phylum level, community composition of the three wFGDs studied here, were similar to those observed by Brown et al. (2012), with Alphaproteobacteria, Betaproteobacteria, Gammaproteobacteria, and Actinobacteria most abundant. Additionally, genera including Hydrogenophilus, Ralstonia, and Pseudomonas were encountered in the current units as well as in previously characterized wFGD slurries (Brown et al., 2012).

\section{Identification of Active Organisms in Unit P}

In previous work, $w F G D$ microbial communities were found to consist of a mixture of thermophilic (e.g., Hydrogenophilus) and mesophilic (e.g., Pseudomonas) taxa (Brown et al., 2012). These observations led to the conclusion that the mesophilic taxa were inactive remnants of the community associated with the freshwater source, while the thermophilic taxa were enriched in the harsh physicochemical setting of the wFGD interior. To identify the active organisms in the wFGD setting, $16 \mathrm{~S}$ rRNA gene sequences in the metatranscriptome from the Unit $\mathrm{P}$ slurry was compared to those in the 16S rRNA gene survey of the Unit $\mathrm{P}$ microbial community (Figure 2A). Taxonomic assignment of $16 \mathrm{~S}$ rRNA in the transcriptome revealed that the most abundant active phyla in Unit P slurry were Firmicutes, Gammaproteobacteria, and Betaproteobacteria (Figure 2A). The Firmicutes-attributable transcripts were assigned to the Enterococcaceae, which have been cultivated from a thermophilic biogas production facility (Maus et al., 2016). The Betaproteobacteria-attributable transcripts were assigned with further taxonomic resolution to the Burkholderiaceae, including Ralstonia/Cupriavidus (Figure 3), of which thermophilic representatives have been isolated (Vandamme and Coenye, 2004; Sheu et al., 2012; Shah et al., 2015). While active
Betaproteobacteria were attributable to potentially thermophilic lineages, this was not the case with the Gammaproteobacteria, among which, transcripts attributable to Moraxellaceae, Pasteurellaceae, Pseudomonadaceae were abundant (Figure 3). These included Psychrobacter, Histophilus, and Pseudomonas. Neither Psychrobacter nor Histophilus contain thermophilic representatives. Psychrobacter are well-known phsychrophiles (Bendia et al., 2018), and Histophilus are obligately parasitic (Hansen et al., 2013). While Pseudomonas spp. are cosmopolitan and observed in non-extreme settings, thermophilic and thermotolerant representatives have been described (Hollocher and Kristjánsson, 1992; Manania and Moore, 2002). Indeed, they are observed among other mesophiles in thermal environments (Droffner et al., 1995), indicating that classifications of organisms typically described as mesophiles are capable of survival and growth at temperatures well outside their described range. In previous work relying only on 16S rRNA gene surveys, it was presumed that these predominantly mesophilic lineages (including Pseudomonas) were present, but inactive components of wFGD microbial communities (Brown et al., 2012), but that does not appear to be the case.

Besides metatranscriptomic evidence of active organisms in Unit P slurry, thermophilic, aerobic, acetate and glucose oxidizing enrichment cultures were recovered in media designed to mimic wFGD chemistry. Growth was assessed based on direct cell counts and glucose or acetate depletion (Supplementary Figure 2). After six transfers in these media and incubation at $55^{\circ} \mathrm{C}$, we detected phylotypes attributable to Pseudomonadaceae (Figure 3). A comparison of the Pseudomonadaceae-affiliated OTU to 16S rRNA gene sequences in the GenBank database using BLASTn (Altschul et al., 1997) revealed that it was most closely related (99\% identity) to a Pseudomonas mendocina strain CB46 from hydrocarbon-contaminated soil (Al-Mailem et al., 2019). Pseudomonads were prominent components of the Unit P microbial community based on the 16S rRNA gene survey, in the metatranscriptome-based community profile, and in enrichment cultures (Figure 3), indicating that these organisms are important and active parts of the microbial community in Unit P. Additionally, organisms attributable to marine, aerobic, organotrophic Idiomarina sp. (Sanz-Sáez et al., 2019), a marine Tenericutes (Fichtel et al., 2012), and a Bacillus subterraneus from $\mathrm{Cr}(\mathrm{VI})$-contaminated soil (Liu et al., 2019) were abundant in enrichment cultures. However, these latter organisms were not prominent components of the Unit $\mathrm{P}$ microbial community as indicated by the 16S rRNA gene sequencing-based survey or taxonomic assignment of $16 \mathrm{~S}$ rRNA in the metatranscriptome (Figure 3).

An analysis of the functions of gene products detected in the Unit $\mathrm{P}$ metatranscriptome provided an indication of the microbial response to the harsh physicochemical conditions of the wFGD interior. Most of the genes detected were attributable to potassium metabolism, carbohydrate metabolism, clustering-based subsystems, and phages and transposable elements (Figure 2B). Clustering-based subsystems are genetic systems with unknown or unclear predicted functions (Overbeek et al., 2005). The relatively high expression of genes involved in potassium metabolism are likely a response 


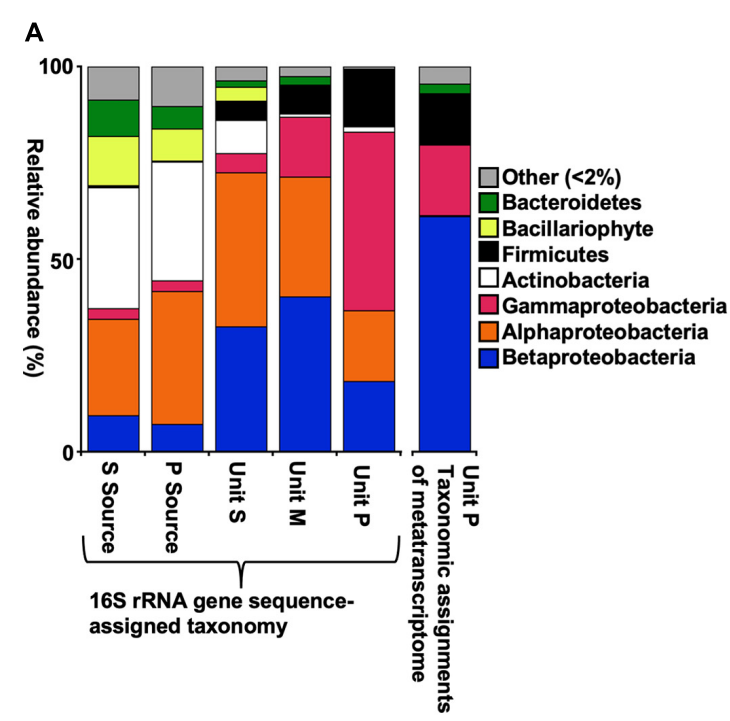

B

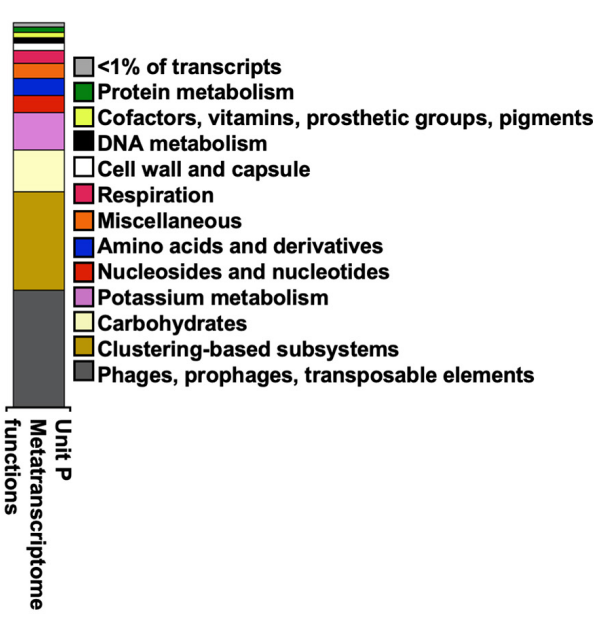

FIGURE 2 | Relative abundances of 16S rRNA gene sequencing-derived OTU at the phylum-level (class-level for Proteobacteria) in wFGD source waters and units, consensus taxonomic assignments of 16S rRNA in the Unit P transcriptome (A), and functional assignments of transcripts detected in Unit P (B).

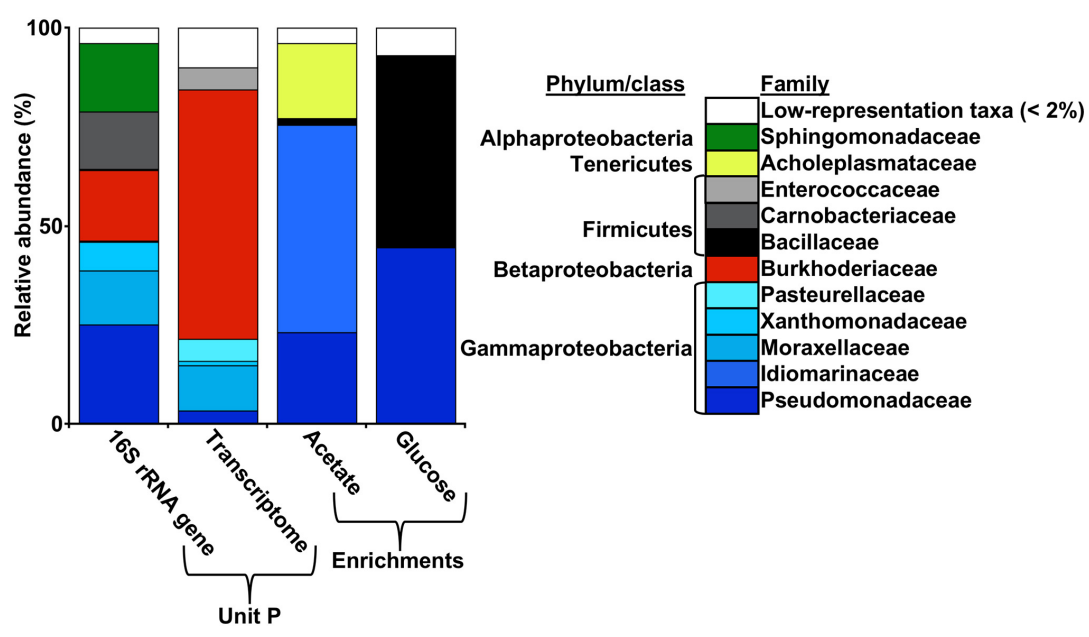

FIGURE 3 | Relative abundances of $16 \mathrm{~S}$ rRNA gene sequencing-derived OTU at the family level, consensus family level taxonomic assignments of $16 \mathrm{~S}$ rRNA in the Unit P transcriptome, and 16S rRNA gene sequencing-derived family level taxonomic composition of aerobic acetate- and glucose-oxidizing enrichment cultures from Unit $P$.

to the osmotic stress associated with the wFGD, which are hypertonic solutions, containing notably high concentrations of chloride, sulfate, magnesium, and calcium (Table 1). Under these conditions, cells may transport $\mathrm{K}^{+}$into the cytoplasm to minimize this osmotic stress imposed by wFGD fluids (Rosen, 1986; Booth and Higgins, 1990; Meury and Kohiyama, 1992; Guitierrez et al., 1995). Genes SEED database (Overbeek et al., 2005) classified in the potassium metabolism subsystem include the $k$ tr potassium uptake systems, which are involved in shortand long-term osmotic stress response (Holtman et al., 2003).

Transcription of genes involved in carbohydrate metabolism, as well as amino acid metabolism (Figure 2B), may have been a response to osmotic stress (e.g., synthesis of osmoprotectants;
Booth and Higgins, 1990; Guitierrez et al., 1995; Poolman and Glaasker, 1998). However, carbohydrate metabolism was also likely devoted to energy recovery, as previous work has shown that $\mathrm{wFGD}$ slurries contain abundant dissolved organic carbon (mostly from fly ash; Brown et al., 2012), and this endogenous organic carbon was likely the major driver of $\mathrm{O}_{2}$ consumption in the respirometry incubations (Figure 1). The prevalence of phage-attributable signals in the transcriptome could be due to "kill the winner" patterns of phage reproduction, whereby relatively rapidly growing organisms are most susceptible to infection (Parmar et al., 2018). Phage appear to be more prominent in microbial communities that are undergoing relatively dramatic physicochemical perturbation and in cases 
where microbial activity is enhanced (Pan et al., 2014; Trubl et al., 2018). Indeed, a metagenomic survey of microbial communities associated with hydraulic fracturing return waters revealed that phage were increasingly prominent when microbial communities from freshwater-based fracking fluid were incubated in hightemperature, hypertonic shale plays (Daly et al., 2019), which could be considered physicochemical analogs of wFGDs.

\section{Impacts of Microbial Activities on Thermoelectric Power Plant Performance}

Thermoelectric power generation (whether coal, natural gas, or nuclear) accounts for approximately $40 \%$ of water withdrawal in the United States, with approximately 500 million cubic meters of water used per day in 2015 (Dieter et al., 2018). This water is used for steam generation, cooling, and waste product capture, transport, and disposal (Yang and Dziegielewski, 2007; Badr et al., 2012; Dieter et al., 2018). In many ways, the water used in electric power generation, represents the circulatory system of the electric power plant, because it facilitates the transfer of energy and material necessary for plant operation. As it circulates, the water and the microorganisms associated with it are exposed to dramatically differing physicochemical conditions. These fluctuating conditions exert control on the microbiological activities which can then influence system performance and environmental impacts of electric power generation. The work here shows some of these shifts.

Despite the importance of freshwater use in thermoelectric power generation the activities of microorganisms in these systems have been mostly unexplored, though invoked as causes of operational problems. A goal of this paper was to establish the composition and activity of microbial communities in wFGDs, and the establishment of activity sets the stage to explore how they influence the performance of thermoelectric power facility performance. For instance, microbiological activities have been suggested to be responsible for excessive foaming in wFGDs and corrosion of steel structures of power plants (Rajendran et al., 1999; Buchart et al., 2006; Moskal, 2011; Brown et al., 2012; Qin et al., 2013, 2014). In the wFGD, microbial activities might be used to enhance the removal of $\mathrm{SO}_{2}$ and gypsum formation (Huber and Stetter, 1998; Zhang and Liu, 2015; Graves et al., 2017; Zhang et al., 2017), while also modulating the redox state of $\mathrm{Hg}$ that passes through the wFGD unit, where $\mathrm{Hg}^{0}$ oxidation could limit its release and $\mathrm{Hg}^{2+}$ reduction could enhance its release into the atmosphere (Barkay and Wagner-Döbler, 2005; Wu et al., 2010; Moretti and Jones, 2012; Ochoa-González et al., 2013). Finally, microbial activities can influence the fate of the most prominent toxic components of solid waste, As, Se, $\mathrm{Pb}$, and $\mathrm{Hg}$ (Gingerich and Mauter, 2020), as well as enhance the removal of toxic dissolved species such as Se (Van Ginkel et al., 2011; Nakajima et al., 2013; Andalib et al., 2016; Córdoba and Staicu, 2018; Gingerich et al., 2018). In all of these scenarios, microbial communities might be subjected to changes in their physicochemical setting as water and suspended solids move through thermoelectric power generation station process points, thus forcing shifts in microbial communities, and potentially, activities. From the perspective of the microorganisms detected in the wFGDs in the current work, the abundant Hydrogenophilus, Hydrogenophaga, and Gallionella, which were abundant in Units S and M, could induce corrosion (Rajala et al., 2015; Huang et al., 2021). Additionally, active organisms in Unit P, including Ralstonia/Cupriavidus spp. and Pseudomonas spp. have been shown to induce steel corrosion as well as $\mathrm{Hg}$ (II) reduction, which could lead to $\mathrm{Hg}$ reemission (Da Silva et al., 2002; Champier et al., 2004; Pepi et al., 2011; Rojas et al., 2011; Li et al., 2016; Jia et al., 2017; Zheng et al., 2018). Organisms within these taxa can also mediate environmentally beneficial processes, such as the reductive immobilization of Se (Roux et al., 2001; Hunter, 2014).

It is also important to note that the same large river system provided the source water for all three of the wFGD units examined here, but despite the similarities in source water-associated microbial communities (Figure 2A), distinct patterns of microbiological community composition and activity were observed in the wFGDs. This observation suggests that power generation station-specific operational characteristics might be responsible for how microbial communities are shaped within different process points of the facilities. Despite the differences among the units, this work shows that a prominent subset of the microbial community in a physicochemically extreme human-made setting is actively metabolizing, and therefore, could influence the performance of that system.

\section{DATA AVAILABILITY STATEMENT}

The datasets presented in this study can be found in online repositories. The names of the repository/repositories and accession number(s) can be found below: https://www.ncbi.nlm. nih.gov/, PRJNA689629.

\section{AUTHOR CONTRIBUTIONS}

GM: conceptualization, data curation, formal analysis, investigation, methodology, validation, visualization, writing original draft, and writing - review and editing. SS: formal analysis, investigation, methodology, supervision, and writing original draft. WR: investigation, methodology, and writing original draft. NS: methodology, project administration, and writing - original draft. JS: conceptualization, data curation, formal analysis, funding acquisition, investigation, methodology, project administration, resources, supervision, writing - original draft, and writing - review and editing. All authors contributed to the article and approved the submitted version.

\section{FUNDING}

This work was supported by the Electric Power Research Institute (Agreement MA10004175). 


\section{ACKNOWLEDGMENTS}

We thank Mark Golightly (FirstEnergy Corp.) for assistance with sample collection and expertise in wFGD operation. We also thank Hazel Barton for the use of her microscopy facility.

\section{REFERENCES}

Albuquerque, L., Santos, J., Travassos, P., Nobre, M. F., Rainey, F. A., Wait, R., et al. (2002). Albidovulum inexpectatum gen. nov., sp. nov., a nonphotosynthetic and slightly thermophilic bacterium from a marine hot spring that is very closely related to members of the phytosynthetic genus Rhodovulum. Appl. Environ. Microbiol. 68, 4266-4273. doi: 10.1128/aem.68.9.4266-4273.2002

Al-Mailem, D. M., Kansour, M. K., and Radwan, S. S. (2019). Crossbioaugmentation among four remote soil samples contaminated with oil exerted just inconsistent effects on oil-bioremediation. Front. Microbiol. 10:2827. doi: 10.3389/fmicb.2019.02827

Altschul, S. F., Madden, T. L., Schagger, A. A., Zhang, J., Zhang, Z., Miller, W., et al. (1997). Gapped BLAST and PSI-BLAST: a new generation of protein database search programs. Nucl. Acids Res. 25, 3389-3402. doi: 10.1093/nar/25.17.3389

Andalib, M., Arabi, S., Dold, P., and Bye, C. (2016). Mathematical modeling of biological selenium removal from flue gas desulfurization (FGD) wastewater treatment. Proc. Wat. Environ. Federat. 11, 228-248. doi: 10.2175/ 193864716819706770

Arsène-Ploetz, F., Koechler, S., Marchal, M., Coppée, J.-Y., Chandler, M., Bonnefoy, V., et al. (2010). Structure, function, and evolution of the Thiomonas spp. genome. PLoS Genet. 6:e1000859. doi: 10.1371/journal.pgen.1000859

Badr, L., Boardman, G., Asce, F., and Bigger, J. (2012). Review of water use in U.S. thermoelectric power plants. J. Energy Engineer. 138, 246-257. doi: 10.1061/ (asce)ey.1943-7897.0000076

Barkay, T., and Wagner-Döbler, I. (2005). Microbial transformations of mercury: potentials, challenges, and achievements in controlling mercury toxicity in the environment. Adv. Appl. Microbiol. 57, 1-56. doi: 10.1016/s0065-2164(05) 57001- 1

Bendia, A. G., Araujo, G. G., Pulschen, A. A., Contro, B., Duarte, R. T. D., Rodrigues, F., et al. (2018). Surviving in hot and cold: psycrophiles and thermophiles from Deception Island volcano, Antarctica. Extremophiles 22, 917-929. doi: 10.1007/s00792-018-1048-1

Bokulich, N. A., Subramanian, S., Faith, J. J., Gevers, D., Gordon, J. I., Knight, R., et al. (2013). Quality filtering vastly improves diversity estimates from Illumina amplicon sequencing. Nat. Meth. 10, 57-59. doi: 10.1038/nmeth. 2276

Booth, I. R., and Higgins, C. F. (1990). Enteric bacteria and osmotic stress: intracellular potassium glutamate as a secondary signal of osmotic stress. FEMS Microbiol. Rev. 75, 239-246. doi: 10.1111/j.1574-6968.1990.tb04097.x

Brown, B. P., Brown, S. R., and Senko, J. M. (2012). Microbial communities associated with wet flue gas desulfurization systems. Front. Microbiol. 3:412. doi: 10.3389/fmicb.2012.00412

Buchart, C. N., Johnsson, J. A., and Kiil, S. (2006). Experimental investigation of the degradation rate of adipic acid in wet flue gas desulphurization plants. Fuel 85, 725-735. doi: 10.1016/j.fuel.2005.08.021

Caporaso, J. G., Kuczynski, J., Stombaugh, J., Bittinger, K., Bushman, F. D., Costello, E. K., et al. (2010). QIIME allows analysis of high-throughput community sequencing data. Nat. Meth. 7, 335-336.

Caporaso, J. G., Lauber, C. L., Walters, W. A., Berg-Lyons, D., Lozupone, C. A., Turnbaugh, P. J., et al. (2011). Global patterns of 16 S rRNA diversity at a depth of millions of sequences per sample. Proc. Nat. Acad. Sci. U.S.A. 108, 4516-4522. doi: $10.1073 /$ pnas. 1000080107

Champier, L., Duarte, V., Michaud-Soret, I., and Covés, J. (2004). Characterization of the MerD protein from Ralstonia metallidurans $\mathrm{CH} 34$ : a possible role in bacterial mercury resistance by switching off the induction of the mer operon. Mol. Microbiol. 52, 1475-1485. doi: 10.1111/j.1365-2958.2004.04071.x

Chen, W.-M., Huang, H.-W., Chang, J.-S., Han, Y.-L., Guo, T.-R., and Sheu, S.-Y. (2013). Tepidimonas fonticaldi sp. nov., a slightly thermophilic betaproteobacterium isolated from a hot spring. Int. J. Syst. Evol. Microbiol. 63, 1810-1816. doi: 10.1099/ijs.0.043729-0

\section{SUPPLEMENTARY MATERIAL}

The Supplementary Material for this article can be found online at: https://www.frontiersin.org/articles/10.3389/fmicb. 2021.675628/full\#supplementary-material

Córdoba, P. (2015). Status of flue gas desulphurisation (FGD) systems from coalfired power plants: overview of the physic-chemical control processes of wet limestone FGDs. Fuel 144, 274-286. doi: 10.1016/j.fuel.2014.12.065

Córdoba, P., and Staicu, L. C. (2018). Flue gas desulfurization effluents: an unexploited seleneium resource. Fuel 223, 268-276. doi: 10.1016/j.fuel.2018. 03.052

Cotta, M. A., Whitehead, T. R., Collins, M. D., and Lawson, P. A. (2004). Atopstipes suicloacale gen. nov., sp. nov., isolated from an underground swine manure storage pit. Anaerobe 10, 191-195. doi: 10.1016/j.anaerobe.2004.04.001

Da Silva, S., Basséguy, R., and Bergel, A. (2002). The role of hydrogenases in the anaerobic microbiologically influenced corrosion of steel. Bioelectrochemistry 56, 77-79. doi: 10.1016/s1567-5394(02)00034-8

Daly, R. A., Roux, S., Borton, M. A., Morgan, D. M., Johnston, M. D., Booker, A. E., et al. (2019). Viruses control dominant bacteria colonizing the terrestrial deep biosphere after hydraulic fracturing. Nat. Microbiol. 4, 352-361. doi: 10.1038/s41564-018-0312-6

Dieter, C. A., Maupin, M. A., Caldwell, R. R., Harris, M. A., Ivahnenko, T. I., Lovelace, J. K., et al. (2018). Estimated Use of Water in the United States in 2015. Reston, VA: United States Geological Survey Circular, 1441.

Droffner, M. L., Frinton, W. F. Jr., and Evans, E. (1995). Evidence for the prominence of well characterized mesophilic bacteria in thermophilic (50-70 $\left.{ }^{\circ} \mathrm{C}\right)$ composting environments. Biomass Bioenergy 8, 191-195. doi: 10.1016/ 0961-9534(95)00002-o

Edgar, R. C. (2010). Search and clustering orders of magnitude faster than BLAST. Bioinformatics 26, 2460-2461. doi: 10.1093/bioinformatics/btq461

Fichtel, K., Mathes, F., Könneke, M., Cypionka, H., and Engelen, B. (2012). Isolation of sulfate reducing bacteria from sediments above the deepsubseafloor aquifer. Front. Microbiol. 3:65. doi: 10.3389/fmicb.2012.00065

Ghosh, W., and Dam, B. (2009). Biochemistry and molecular biology of lithotrophic sulfur oxidation by taxonomically and ecologically diverse bacteria and archaea. FEMS Microbiol. Rev. 33, 999-1043. doi: 10.1111/j.1574-6976. 2009.00187.x

Gingerich, D. B., Grol, E., and Mauter, M. S. (2018). Fundamental challenges and engineering opportunities in flue gas desulfurization wastewater treatment at coal fired power plants. Environ. Sci. Wat. Res. Technol. 4:909. doi: 10.1039/ c8ew00264a

Gingerich, D. B., and Mauter, M. S. (2020). Flue gas desulfurization wastewater composition and implications for regulatory and treatment train design. Environ. Sci. Technol. 54, 3783-3792. doi: 10.1021/acs.est.9b07433

Graves, D., Smith, J. J., Chen, L., Kreinberg, A., Wallace, B., and White, R. (2017). Biogeochemical oxidation of calcium sulfite hemihydrate to gypsum in flue gas desulfurization byproduct using sulfur-oxidizing bacteria. J. Environ. Management. 201, 357-365. doi: 10.1016/j.jenvman.2017.06.013

Guitierrez, C., Abee, T., and Booth, I. R. (1995). Physiology of the osmotic stress response in microorganisms. Int. J. Food Microbiol. 28, 233-244. doi: 10.1016/ 0168-1605(95)00059-3

Hahn, M. W., Jezberová, J., Koll, U., Saueressig-Beck, T., and Schmidt, J. (2016). Complete ecological isolation and cryptic diversity in Polynucleobacter bacteria not resolved by 16 S rRNA gene sequences. ISME J. 10, 1642-1655. doi: 10.1038/ ismej.2015.237

Hallbeck, L., and Pedersen, K. (1991). Autotrophic and mixotrophic growth of Gallionella ferruginea. J. Gen. Microbiol. 137, 2657-2661. doi: 10.1099/ 00221287-137-11-2657

Hansen, M. J., Bertelsen, M. F., Dietz, R., Sonne, C., and Bojesen, A. M. (2013). A simple and novel method for retrieval of Pasteurellaceae from swab samples collected in the field. Microbiol. Open. 2, 795-797. doi: 10.1002/mbo3.114

Hayashi, N. R., Ishida, T., Yokota, A., Kodama, T., and Igarashi, Y. (1999). Hydrogenophilus thermoluteolus gen. nov., sp. nov., a thermophilic, facultatively chemolithoautotrophic, hydrogen-oxidizing bacterium. Int. J. Syst. Bacteriol. 49, 783-786. doi: 10.1099/00207713-49-2-783 
Hollocher, T. C., and Kristjánsson, J. K. (1992). Thermophilic denitrifying bacteria: a survey of hot springs in southwestern Iceland. FEMS Microbiol. Ecol. 10, 113-119. doi: 10.1016/0168-6496(92)90052-u

Holtman, G., Bakker, E. P., Uozumi, N., and Bremer, E. (2003). KtrAB and KtrCD: two $\mathrm{K}^{+}$uptake systems in Bacillus subtilis and their role in adaptation to hypertonicity. J. Bacteriol. 185, 1289-1298. doi: 10.1128/jb.185.4.1289-1298. 2003

Huang, Y., Xu, D., Huang, L., Luo, Y., Muhadesi, J.-B., Qian, H., et al. (2021). Responses of soil microbiome to steel corrosion. Biofilms Microbiomes 7:6.

Huber, H., and Stetter, K. O. (1998). Hyperthermophiles and their possible role in biotechnology. J. Biotechnol. 64, 39-52. doi: 10.1016/s0168-1656(98)00102-3

Hunter, W. J. (2014). Pseudomonas seleniipraecipitans proteins potentially involved in selenite reduction. Curr. Microbiol. 69, 69-74. doi: 10.1007/s00284-0140555-2

Jia, R., Yang, D., Xu, D., and Gu, T. (2017). Anaerobic corrosion of 304 stainless steel caused by the Pseudomonas aeruginosa biofilm. Front. Microbiol. 8:2335. doi: $10.3389 /$ fmicb.2017.02335

Leys, N. M. E. J., Ryngaert, A., Bastiaens, L., Verstraete, W., Top, E. M., and Springael, D. (2004). Occurrence and phylogenetic diversity of Sphingomonas strains in soils contaminated with polycyclic aromatic hydrocarbons. Appl. Environ. Microbiol. 70, 1944-1955. doi: 10.1128/aem.70.4.1944-1955.2004

Li, H., Zhou, E., Zhang, D., Xu, D., Xia, J., Yangm, C., et al. (2016). Microbiologially influenced corrosion of 2707 hyper-duplex stainless steel by marine Pseudomonas aeruginosa biofilm. Sci. Rep. 6:20190.

Likens, G. E., Driscoll, C. T., and Buso, D. C. (1996). Long-term effects of acid rain: response and recovery of a forest ecosystem. Science 272, 244-246. doi: 10.1126/science.272.5259.244

Liu, B., Su, G., Yang, Y., Yao, Y., Huang, Y., Hu, L., et al. (2019). Vertical distribution of microbial communities in chromium-contaminated soil and isolation of Cr(VI)-reducing strains. Ecotox. Environ. Safety 180, 242-251. doi: 10.1016/ j.ecoenv.2019.05.023

Lozupone, C., and Knight, R. (2005). UniFrac: a new phylogenetic method for comparing microbial communities. Appl. Environ. Microbiol. 71, 8228-8235. doi: $10.1128 /$ aem.71.12.8228-8235.2005

Manania, C. M., and Moore, E. R. B. (2002). Pseudomonas thermotolerans sp. nov., a thermotolerant speces of the genus Pseudomonas sensu stricto. Int. J. Syst. Evol. Microbiol. 52, 2203-2209. doi: 10.1099/00207713-52-6-2203

Maus, I., Koek, D. E., Cibis, K. G., Hahnke, S., Kim, Y. S., Langer, T., et al. (2016). Unraveling the microbiome of a thermophilic biogas plant by metagenome and metatranscriptome analysis complemented by characterization of bacterial and archaeal isolates. Biotechnol. Biofuel. 9:171.

Merino, N., Aronson, H., Bojanova, D. P., Feyhl-Buska, J., Wong, M. L., Zhang, S., et al. (2019). Living at the extremes: extremophiles and the limits of live in a planetary context. Front. Microbiol. 10:780. doi: 10.3389/fmicb.2019.00780

Meury, J., and Kohiyama, M. (1992). Potassium ions and changes in bacterial DNA supercoiling under osmotic stress. FEMS Microbiol. Lett. 99, 159-164. doi: 10.1111/j.1574-6968.1992.tb05559.x

Meyer, F., Paarmann, D., D’Souza, M., Olson, R., Glass, E. M., Kubal, M., et al. (2008). The metagenomics RAST server - a public resource for the automatic phylogenetic and functional analysis of metagenomes. BMC Bioinform. 9:386. doi: 10.1186/1471-2105-9-386

Moretti, A. L., and Jones, C. S. (2012). Power-Gen Asia, Advanced Emission Control Technologies for Coal-Fired Power Plants. Bankok: Babcock \& Wilcox Power Generation Group Technical Paper BR-1886.

Moskal, M. (2011). EPRI corrosion of wet flue gas desulfurization systems. Conduit $11,1-2$.

Nakajima, T., Kamito, R., Takanashi, H., and Ohki, A. (2013). Reduction of selenate from simulated wet flue gas desulfurization wastewater using photocatalyst and microorganism. J. Wat. Environ. Technol. 11, 419-427. doi: 10.2965/jwet.2013. 419

Ochoa-González, R., Díaz-Somoano, M., and Martínez-Tarazona, M. R. (2013). The retention capacity for trace elements by the flue gas desulphurization system under operational conditions of a co-combustion power plant. Fuel 105, $112-118$.

Ohio River Valley Water Sanitary Commission (ORANCO) (2018). Assessment of Ohio River Water Quality Conditions 2012-2016. Cincinnati, OH: Ohio River Valley Water Sanitation Commission.
Overbeek, R., Begley, T., Butler, R. M., Choudhuri, J. V., Chuang, H.-Y., Cohoon, M., et al. (2005). The subsystems approach to genomc annotation and its use in the Project to Annotate 1000 Genomes. Nucl. Acid Res. 33, 5691-5702. doi: 10.1093/nar/gki866

Pan, D., Watson, R., Wang, D., Tan, Z. H., Snow, D. D., and Weber, K. A. (2014). Correlation between viral production and carbon mineralization under nitrate reducing conditions in aquifer sediment. ISME J. 8, 1691-1703. doi: 10.1038/ ismej.2014.38

Parmar, K., Dafale, N., Pal, R., Takariha, H., and Purohit, H. (2018). An insight into phage diversity at environmental habitats using comparative metagenomics approach. Curr. Microbiol. 75, 132-141. doi: 10.1007/s00284-017-1357-0

Pepi, M., Gaggi, C., Bernardini, E., Focardi, S., Lobianco, A., Ruta, M., et al. (2011). Mercury resistant bacterial strains Pseudomonas and Psychrobacter spp. isolated from sediments of Orbetello Lagoon (Italy) and their possible use in bioremediation process. Int. Biodeterior. Biodeg. 65, 85-91. doi: 10.1016/j.ibiod. 2010.09.006

Poncelet, D. M., Cavender, N., Cutright, T. J., and Senko, J. M. (2013). An assessment of microbial communities associated with surface mining-disturbed overburden. Environ. Monit. Assess. 186, 1917-1929. doi: 10.1007/s10661-0133505-8

Poolman, B., and Glaasker, E. (1998). Regulation of compatible solute accumulation in bacteria. Mol. Microbiol. 29, 397-407. doi: 10.1046/j.13652958.1998.00875.x

Price, M. N., Dehal, P. S., and Arkin, A. P. (2010). FastTree 2-approximately maximum likelihood trees for large alignments. PLoS One 5:e9490. doi: 10.1371/ journal.pone.0009490

Qin, S., Hansen, B. B., and Kiil, S. (2013). Foaming in wet flue gas desulfurization plants: laboratory-scale investigation of long-term performance of antifoaming agents. AIChE J. 59, 3741-3747. doi: 10.1002/aic.14135

Qin, S., Hansen, B. B., and Kiil, S. (2014). Effects of foaming and antifoaming agents on the performance of a wet flue gas desulfurization pilot plant. AIChE J. 60, 2382-2388. doi: 10.1002/aic.14428

Quast, C., Pruesse, E., Yilmaz, P., Gerken, J., Schweer, T., Yarza, P., et al. (2013). The SILVA ribosomal RNA gene database project: improved data processing and web-based tools. Nucl. Acid Res. 41, D590-D596.

Rajala, P., Carpén, L., Vespäläinen, M., Raulio, M., Sohlberg, E., and Bomberg, M. (2015). Microbially induced corrosion of carbon steel in deep groundwater environment. Front. Microbiol. 6:647. doi: 10.3389/fmicb.2015.00647

Rajendran, N., Latha, G., Ravichandran, K., and Rajeswari, S. (1999). Flue gas desulfurization systems - a review. Corr. Rev. 17, 443-465.

Rojas, L. A., Yá nez, C., Bonzález, M., Lobos, S., Smalla, K., and Seeger, M. (2011). Characterization of the metabolically modified heavy metalresistant Cupriavidus metallidurans strain MSR33 generated for mercury bioremediation. PLoS One 6:e17555. doi: 10.1371/journal.pone.0017555

Rosen, B. P. (1986). Recent advances in bacterial ion transport. Ann. Rev. Microbiol. 40, 263-286. doi: 10.1146/annurev.mi.40.100186.001403

Roux, M., Sarret, G., Pignot-Paintrand, I., Fontecave, M., and Coves, J. (2001). Mobilization of selenite by Ralstonia metallidurans CH34. Appl. Environ. Microbiol. 67, 769-773. doi: 10.1128/aem.67.2.769-773.2001

Salcher, M. M., Pernthaler, J., and Piosch, T. (2011). Seasonal bloom dynamics and ecophysiology of the freshwater sister clade of SAR11 bacteria 'that rule the waves' (LD12). ISME J. 5, 1242-1252. doi: 10.1038/ismej.2011.8

Sanz-Sáez, I., Salazar, G., Lara, E., Royo-Llonch, M., Vaqué, D., Duarte, C. M., et al. (2019). Diversity patterns of marine heterotrophic culturable bacteria along vertical and latitudinal gradients. bioRxiv [preprint] doi: 10.1101/774992

Schönfeld, J., Heuer, H., van Elsas, J. D., and Smalla, K. (2003). Specific and sensitive detection of Ralstonia solanacearum in soil on the basis of PCR amplification of fliC fragments. Appl. Environ. Microbiol. 69, 7248-7256. doi: 10.1128/aem.69.12.7248-7256.2003

Schultz, G. E. Jr., Kovatch, J. J., and Anneken, E. M. (2013). Bacterial diversity in a large, temperate, heavily modified river, as determined by pyrosequencing. Aqat. Microbial. Ecol. 70, 169-179. doi: 10.3354/ame01646

Shah, A. A., Nawaz, A., Kanwal, L., Hasan, F., Khan, S., and Badshah, M. (2015). Degradation of poly( $\varepsilon$-caprolactone) by a thermophilic bacterium Ralstonia sp. strain MRL-TL isolated from hot spring. Int. Biodeterior. Biodegrad. 98, 35-42. doi: 10.1016/j.ibiod.2014.1 1.017 
Sheu, D.-S., Chen, W.-M., Lai, Y.-W., and Chang, R.-C. (2012). Mutations derived from the thermophilic polyhydroxyalkanoate synthase $\mathrm{PhaC}$ enhance the thermostability and activity of PhaC from Cupriavidus necator H16. J. Bacteriol. 194, 2620-2629. doi: 10.1128/jb.06543-11

Srivastava, R. K., Hutson, N., Martin, B., Princiotta, F., and Staudt, J. (2006). Control of mercury emissions from coal-fired electric utility boilers. Environ. Sci. Technol. 40, 1385-1393. doi: 10.1021/es062639u

Srivastava, R. K., and Jozewicz, W. (2001). Flue gas desulfurization: the state of the art. J. Air Waste Management Assoc. 51, 1676-1688.

Stannish, L. F., Hull, N. M., Robertson, C. E., Harris, J. K., Stevens, M. J., Spear, J. R., et al. (2016). Factors influencing bacterial diversity and community composition in municipal drinking waters in the Ohio River Basin, USA. PLoS One 11:e0157966. doi: 10.1371/journal.pone.0157966

Tanner, R. S. (1997). "Cultivation of bacteria and fungi," in Manual of Environmental Microbiology, eds C. J. Hurst, G. R. Knudsen, M. J. McInerney, L. D. Stetzenbach, and M. V. Walter (Washington, DC: ASM Press), 52-59.

Trubl, G., Jang, H. B., Roux, S., Emerson, J. B., Solonenko, N., Vik, D. R., et al. (2018). Soil viruses are underexplored players in ecosystem carbon processing. mSystems 3, e76-e18.

Turekian, K. K. (1968). Oceans. Hoboken, NJ: Prentice-Hall.

U.S. Energy Information Agency (USEIA) (2020). What Is U.S. Electricity Generation by Energy Source?. Available online at: https:/www.eia.gov/tools/ faqs/faq.php?id=427\&t=21 (accessed September 4, 2020).

Van Ginkel, S. W., Yang, Z., Kim, B.-O., Sholin, M., and Rittman, B. E. (2011). The removal of selenate to low ppb levels from flue gas desulfurization brine using the $\mathrm{H}_{2}$-based membrane biofilm reactor (MBfR). Bioresource Technol. 102, 6360-6364. doi: 10.1016/j.biortech.2011.03.010

Vandamme, P., and Coenye, T. (2004). Taxonomy of the genus Cupriavidus: a tale of lost and found. Int. J. Syst. Evol. Microbiol. 54, 2285-2289. doi: 10.1099/ijs.0. 63247-0

Wang, Q., Garrity, G. M., Tiedje, J. M., and Cole, J. R. (2007). Naive Bayesian classifier for rapid assignment of rRNA sequences into the new bacterial taxonomy. Appl. Environ. Microbiol. 73, 5261-5267. doi: 10.1128/aem.0006207

Warnecke, F., Amann, R., and Pernthaler, J. (2004). Actinobacterial 16S rRNA genes from freshwater habitats cluster in four distinct lineages. Environ. Microbiol. 6, 242-253. doi: 10.1111/j.1462-2920.2004.00561.x

Werner, J. J., Koren, O., Hugenholtz, P., DeSantis, T. Z., Walters, W. A., Caporaso, J. G., et al. (2012). Impact of training sets on classification of high-throughput bacterial 16S rRNA gene surveys. ISME J. 6, 94-103. doi: 10.1038/ismej.2011.82

Wilke, Z., Harrison, T., Wilkening, J., Field, D., Glass, E. M., Kyrpides, N., et al. (2012). The M5nr: a novel non-redundant database containing protein sequences and annotations from multiple sources and associated tools. BMC Bioinform. 13:141. doi: 10.1186/1471-2105-13-141

Willems, A., Busse, J., Goor, M., Pot, B., Falsen, E., Jantzen, E., et al. (1989). Hydrogenophaga, a new genus of hydrogen-oxidizing bacteria that includes Hydrogenophaga flava comb. nov. (formerly Pseudomonas flava), Hydrogenophaga palleronii (formerly Pseudomonas palleronii), Hydrogenophaga pseudoflava (formerly Pseudomonas pseudoflava and "Pseudomonas carboxydoflava"), and Hydrogenophaga taeniospiralis (formerly Pseudomonas taeniospiralis). Int. J. Syst. Bacteriol. 39, 319-333. doi: 10.1099/00207713-39-3-319

Wu, C.-L., Cao, Y., He, C.-C., Dong, Z.-B., and Pan, W.-P. (2010). Study of elemental mercury re-emission through lab-scale simulated scrubber. Fuel 89 , 2072-2080. doi: 10.1016/j.fuel.2009.11.045

Xu, Z., Te, S. H., He, Y., and Gin, K. Y.-H. (2018). The characteristics and dynamics of cyanobacteria-heterotrophic bacteria between two estuarine reservoirs tropical versus sub-tropical regions. Front. Microbiol. 9:2531. doi: 10.3389/ fmicb.2018.02531

Yang, X., and Dziegielewski, B. (2007). Water use by thermoelectric power plants in the United States. J. Am. Wat. Resources. Assoc. 43, 160-169. doi: 10.1111/j. 1752-1688.2007.00013.x

Zhang, J., Li, L., and Liu, J. (2017). Effects of irrigation and water content of packing materials on a thermophilic biofilter for $\mathrm{SO}_{2}$ removal: performance, oxygen distribution and microbial population. Biochem. Eng. J. 118, 105-112. doi: 10.1016/j.bej.2016.11.015

Zhang, J., and Liu, J. (2015). Thermophilic biofilter for $\mathrm{SO}_{2}$ removal: performance and microbial characteristics. Bioresouce Technol. 180, 106-111. doi: 10.1016/j. biortech.2014.12.074

Zheng, R., Wu, S., Ma, N., and Sun, C. (2018). Genetic and physiological adaptations of marine bacterium Pseudomonas stutzeri 273 to mercury stress. Front. Microbiol. 9:682. doi: 10.3389/fmicb.2018.00682

Conflict of Interest: The authors declare that the research was conducted in the absence of any commercial or financial relationships that could be construed as a potential conflict of interest.

Copyright (C) 2021 Martin, Sharma, Ryan, Srinivasan and Senko. This is an openaccess article distributed under the terms of the Creative Commons Attribution License (CC BY). The use, distribution or reproduction in other forums is permitted, provided the original author(s) and the copyright owner(s) are credited and that the original publication in this journal is cited, in accordance with accepted academic practice. No use, distribution or reproduction is permitted which does not comply with these terms. 